\title{
MENSURAÇÃO DAS MANIFESTAÇÕES PATOLÓGICAS NAS FACHADAS DO ANEXO I DO CAMPUS DA SAÚDE DA UFRGS
}

\author{
SILVA, THAIS DO SOCORRO DA \\ Mestranda em Engenharia Civil \\ PPGCI/UFRGS \\ Rio Grande do Sul, Brasil \\ thaisdosocorro9@gmail.com
}

\author{
PASINATTO, VANESSA
}

Mestranda em Engenharia Civil

PPGCI/UFRGS

Rio Grande do Sul, Brasil

vanepasinatto@gmail.com

\section{GIORDANI, CAROLINE}

Doutoranda em Engenharia Civil

PPGCI/UFRGS

Rio Grande do Sul, Brasil

giordani.carol@gmail.com

\author{
DESSUY, THAINÁ YASMIN \\ Mestranda em Engenharia Civil \\ PPGCI/UFRGS \\ Rio Grande do Sul, Brasil \\ thaiydessuy@hotmail.com
}

\author{
MAZZUCO, MARCELO \\ Mestrando em Engenharia Civil \\ PPGCI/UFRGS \\ Rio Grande do Sul, Brasil \\ marcelo-mazzuco@igp.rs.gov.br
}

\author{
MASUERO, ANGELA BORGES \\ Professora Doutora em Engenharia Civil \\ PPGCI/UFRGS \\ Rio Grande do Sul, Brasil \\ angela.masuero@ufrgs.br
}

\section{RESUMO}

As manifestações patológicas nas edificações, principalmente nas fachadas, provêm de problemas multifatoriais e podem desencadear consequências estéticas, funcionais e até estruturais, sendo que estas últimas são as mais severas para a construção e para o usuário. O objetivo do trabalho foi analisar e mensurar as manifestações patológicas presentes nas fachadas do prédio anexo I do Campus da Saúde - UFRGS, em Porto Alegre. A metodologia empregada foi composta pela identificação dos danos, através de uma análise visual e de ensaios in situ. Após o levantamento, foi confeccionado o mapa de danos e a quantificação das manifestações, utilizando o método de Mensuração de Degradação. A anomalia observada com maior frequência foi manchamento por sujidade, ocasionado principalmente pela vegetação e alto tráfego de veículos no entorno da edificação. Também foram identificados descolamentos e desplacamentos no revestimento, os quais oferecem risco à integridade física dos usuários. Os resultados obtidos possibilitam fornecer subsídios para propostas de intervenção, objetivando a recuperação das condições estéticas, funcionais e de segurança desejadas.

Palavras-chave: Manifestações patológicas, degradação, mensuração, fachada.

\begin{abstract}
Pathological manifestations in buildings, especially in facades, arise from multifactorial problems and can trigger aesthetic, functional and even structural consequences, which can be severe for the construction and the user. The objective of this study was to analyze and measure the pathological manifestations present in the facades of the Annex I building - Health Campus - UFRGS, in Porto Alegre. The methodology used was the identification of damage through visual analysis and in situ tests, such as the percussion test. After the survey stage, the damage map was made and the identified manifestations were quantified using the Degradation Measurement method. The pathological manifestation most frequently observed on all the facades was dirt stain, mainly caused by vegetation and high vehicle traffic around the building. However, detachments of the coating were also identified, which represents a risk to the physical integrity of users. The results of this study enable provide subsidies for intervention proposals, aiming at the recovery of the desired aesthetic, functional and safety conditions.
\end{abstract}

Keywords: Pathological manifestations, damage, measurement, facades. 


\section{INTRODUÇÃO}

Os sistemas de fachadas constituem o invólucro externo das edificações e, dessa maneira, são responsáveis pelas trocas existentes entre o ambiente exterior e interior. Com o objetivo de aumentar a durabilidade e o desempenho das edificações, as fachadas recebem diversos tipos de revestimentos, os quais, muitas vezes, não são imunes às manifestações patológicas, ocasionando danos estéticos ou mesmo danos que comprometem o desempenho do sistema como um todo, podendo, assim, apresentar riscos aos usuários dessas edificações (TERRA, 2001; FLORES-COLEN $e t$ al., 2009).

A realização de inspeções visuais do estado de degradação das fachadas, aliadas a ensaios in situ e em laboratório, permitem caracterizar os mecanismos de degradação atuantes no revestimento e as propriedades relacionadas ao seu desempenho em serviço. Um diagnóstico adequado pode então ser fornecido, conduzindo à propostas de intervenção assertivas (FLORES-COLEN et al., 2009), as quais têm a finalidade de recuperar as características dos materiais do revestimento requeridas em projeto que foram perdidas ao longo da sua vida útil, de forma a capacitá-los novamente a desempenharem suas funções (CASCUDO, CARASEK, 1997).

$\mathrm{O}$ revestimento de fulget é um material à base de cimento com adição de diferentes agregados, provenientes, entre outros, de mármores, granitos, calcários, arenitos, quartzos (KONDO, 2003). Na sua composição, podem ainda ser acrescidas adições minerais, cal e óxido de ferro, além de pigmentos e corantes capazes de proporcionar colorações diferenciadas. Um dos problemas deste tipo de revestimento é a possibilidade de migração de água para seu interior devido sua elevada porosidade superficial, gerando o desenvolvimento de manifestações patológicas, como descolamentos e desplacamentos (PAIM et al., 2016).

Outro revestimento que compõe as fachadas analisadas é o de pastilhas cerâmicas, que consiste, principalmente, em peças constituídas por argilas e outras matérias-primas inorgânicas, as quais são submetidas a altas temperaturas para adquirir suas propriedades relacionadas à absorção de água, expansão por umidade, resistência à flexão, à abrasão, ao ataque químico, entre outras (REBELO, 2010). Esse sistema é constituído de diferentes materiais, sendo substrato, chapisco, emboço, argamassa colante, peças cerâmicas e rejunte, os quais interagem entre si. O resultado da interação entre materiais com propriedades físicas, químicas, térmicas e higrotérmicas distintas, é o surgimento de tensões entre as camadas que geram movimentações, mesmo que não haja ação de cargas mecânicas externas aplicadas. Quando essas movimentações são restringidas, resultam no aparecimento de fissuras e descolamentos (ABREU et al., 2004; PEZZATO, 2010).

Considerando o contexto citado anteriormente, o presente trabalho tem como objetivo mensurar as manifestações patológicas das fachadas do Anexo I do Campus Saúde da Universidade Federal do Rio Grande do Sul (UFRGS), localizado na cidade de Porto Alegre - RS, sendo que este edifício tem sua fachada revestida por dois tipos de revestimentos: fulget e revestimento cerâmico. Diante disso, este artigo aborda e elenca, qualitativamente e quantitativamente, as manifestações patológicas identificadas no revestimento das fachadas do prédio do Anexo I do Campus da Saúde da UFRGS através do método do fator de danos da edificação, conforme Silva (2014).

\section{METODOLOGIA}

A caracterização do prédio, seu entorno e localização são fatores influentes nas manifestações patológicas, visto que podem atuar como possíveis causas de anomalias. Dessa forma, apresenta-se a contextualização da edificação e a metodologia para levantamento e quantificação dos danos presentes nas fachadas.

\subsection{Caracterização da edificação}

A edificação analisada por esse estudo é o prédio do Anexo I do Campus da Saúde da Universidade Federal do Rio Grande do Sul (UFRGS), contituído de três pavimentos com três módulos interligados por ligeiros recuos curvos que criam negativos entre os diferentes elementos da composição. O revestimento da fachada é constituído de fulget (de cor acinzentada, que estão dispostos em grandes placas moldadas in loco com juntas de movimentação) e revestimento cerâmico (com pastilhas quadradas de dimensão $5 \mathrm{~cm} \times 5 \mathrm{~cm}$, cor verde e cinza, e rejunte cor cinza), conforme identificados na figura 1 . 


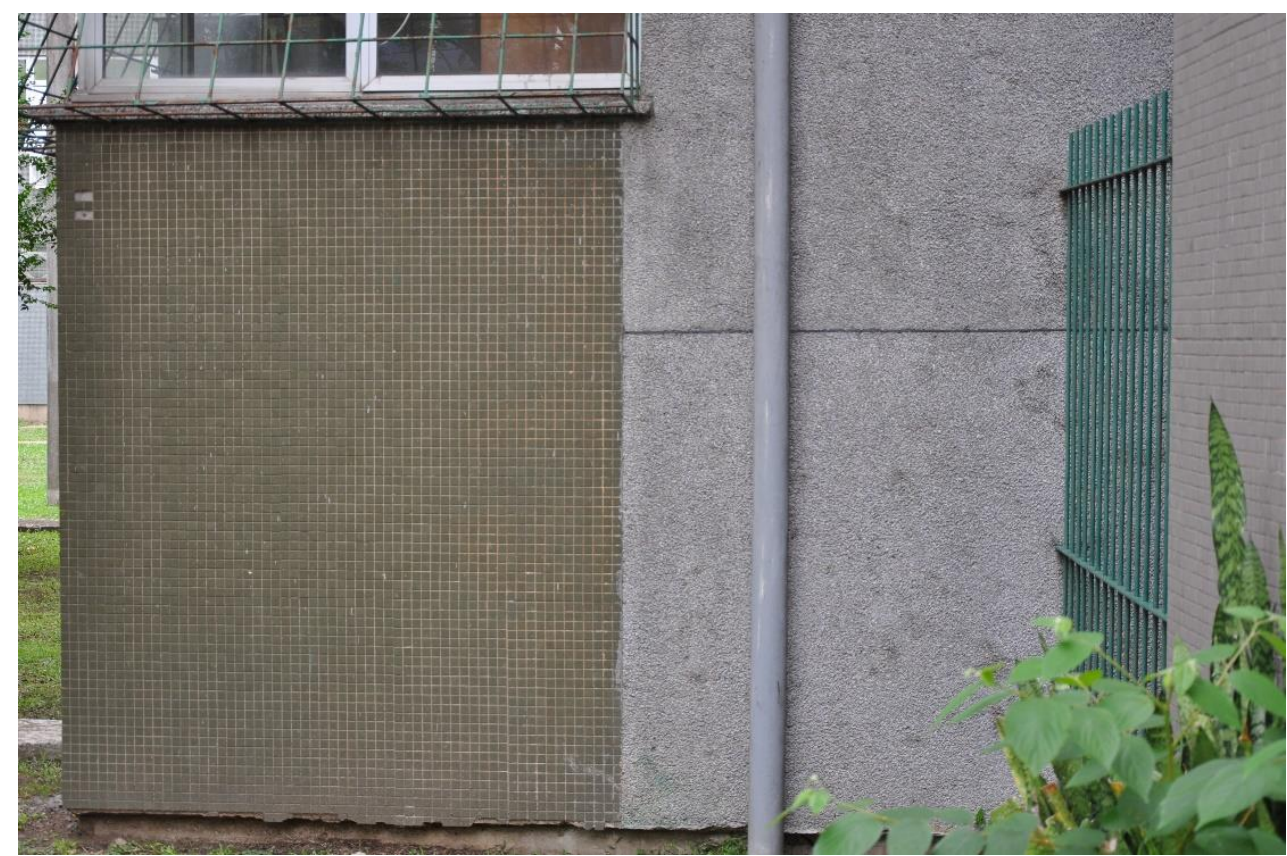

Figura 1: Revestimentos cerâmico (de cor verde, à esquerda) e fulget (de cor cinza, à direita)

A edificação está localizada na cidade de Porto Alegre - RS, submetida às condições climáticas dessa região, a qual apresenta as quatro estações bem definidas e com amplitude térmica diária de até $20{ }^{\circ} \mathrm{C}$ (INMET, 2019). Faz divisa com bairro essencialmente residencial, com grande existência de área de vegetação, condições essas que podem vir a influenciar no desempenho da edificação, visto que tendem a aumentar ou reduzir o grau de exposição às chuvas, à ação do vento e à incidência de radiação solar. Apresenta-se próxima de duas ruas com elevada movimentação de veículos (Rua Ramiro Barcelos e Avenida Ipiranga), e do Arroio Dilúvio, cujas águas apresentam qualidade comprometida pelo quadro avançado de poluição (DAL FORNO, MATOS; 2016). A figura 2 representa o entorno da edificação.
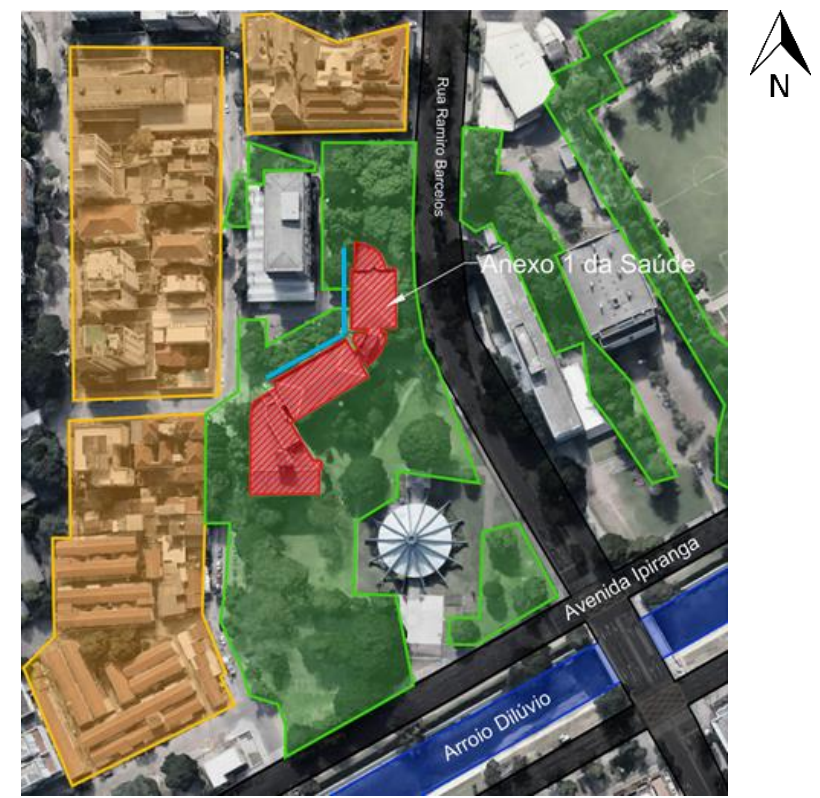

Figura 2: Localização e entorno da edificação do Anexo I do Campus da Saúde da UFRGS

\subsection{Levantamento das manifestações patológicas}

Para identificar possíveis anomalias existentes no revestimento de fachada e realizar seu levantamento, primeiramente, realizou-se a inspeção visual para identificar o estado de conservação do revestimento de fachada a partir de visitas in 
loco, buscando identificar os danos presentes no sistema. Para tal, foram considerados os detalhes construtivos, os tipos de revestimento e as orientações das fachadas, visto que esses fatores podem influenciar no surgimento de manifestações patológicas, impactando no desempenho do sistema de revestimento.

O levantamento fotográfico auxiliou na confecção de um croqui da edificação, no qual foram locados os danos presentes no revestimento. Além disso, o ensaio de percussão foi executado para identificar possíveis problemas de aderência do revestimento, utilizando-se um martelo de madeira para aplicar impactos leves sobre o revestimento, em um altura máxima de 2 metros, a fim de localizar sons cavos (indicando a falta de aderência).

A partir das informações coletadas na edificação, foi possível produzir um mapa de danos, como mostrado na figura 3. Para tal, utilizou-se o software gráfico AutoCAD (AUTODESK, 2017) para representar as anomalias encontradas in loco nos projetos de fachada fornecidos pela SUINFRA-UFRGS (Superintendência de Infraestrutura da Universidade Federal do Rio Grande do Sul). Para efeito de identificação, cada fachada foi nomeada a partir da sua orientação geográfica e divididas em 12 amostras (ZINI et al., 2019). Os mapas de danos produzidos nessa etapa serviram de subsídio para a quantificação dos dados realizados posteriormente, as pranchas não serão apresentadas no escopo desse trabalho.

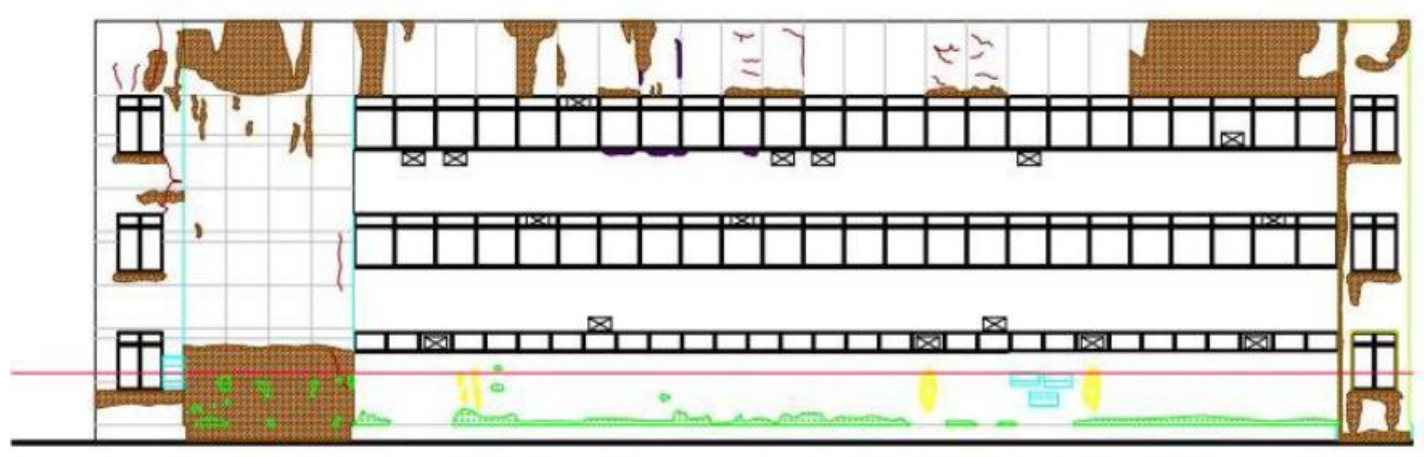

FACHADA 1
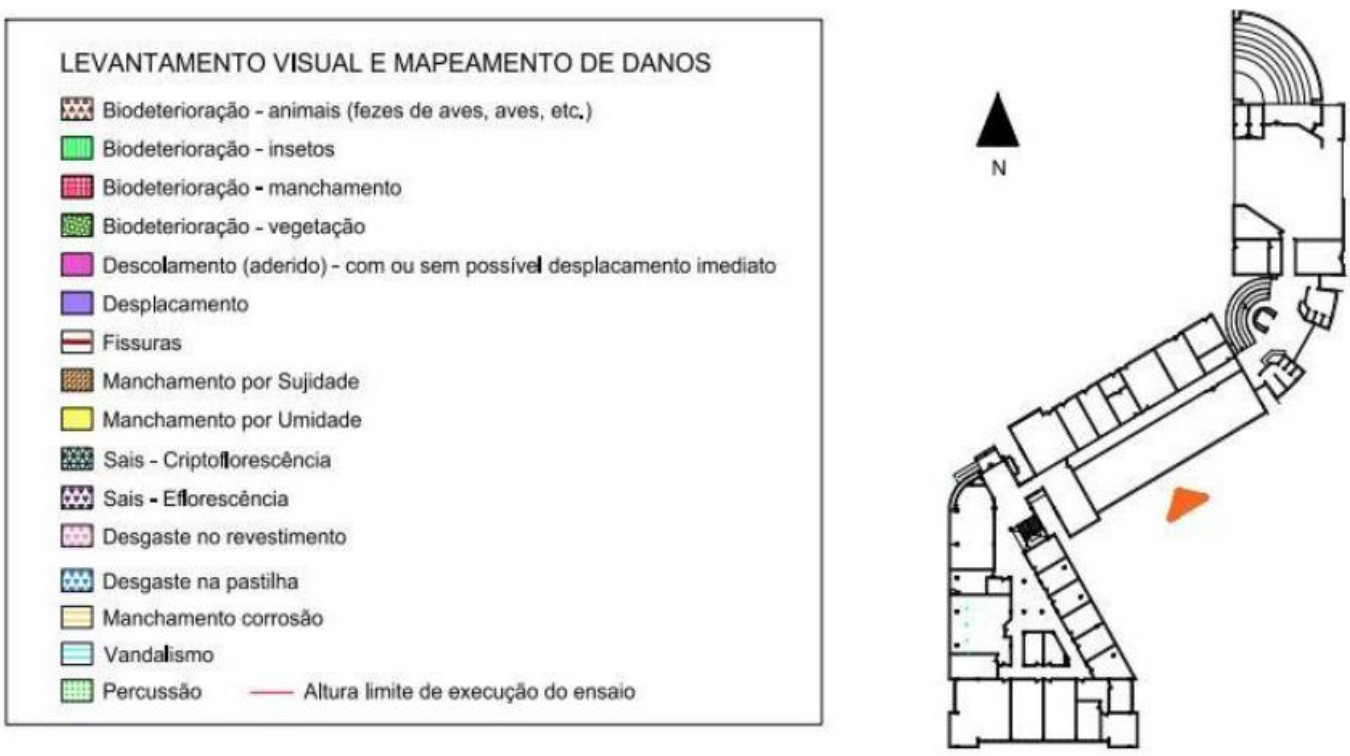

Figura 3: Mapa de danos e localização da fachada 1 da edificação, apresentando a legenda

\subsection{Quantificação das manifestações patológicas}

Primeiramente realizou-se uma qualificação preliminar, que agrupou todas as manifestações patológicas identificadas durante o levantamento. Nessa verificação foi possivel observar a frequencia de ocorrência das anomalias em toda a edificação. A análise também foi realizada distinguindo os dois tipos de revestimento existentes no prédio, para averiguar se há alguma influencia do tipo de revestimento no surgimento de certa anomalia. 
Para realizar a quantificação da degradação do revestimento de fachada, foi utilizado o método de "Mensuração da Degradação", o qual busca auxiliar na avaliação do revestimento e na determinação do pano mais afetado. O método, desenvolvido por Silva (2014), utiliza o fator de danos (FD) para avaliar o desempenho do revestimento. Assim, uma malha de $0,25 \mathrm{~m}^{2}(0,50 \mathrm{~m} \times 0,50 \mathrm{~m})$ foi sobreposta ao desenho técnico com os danos para determinação da área afetada. A figura 4 representa uma das fachadas com a malha, sendo possível quantificar a extensão do pano de fachada que apresenta manifestações patológicas contabilizando os quadrados abrangidos por esta, e que é utilizado no cálculo do fator de danos da edificação (SILVA, 2014).

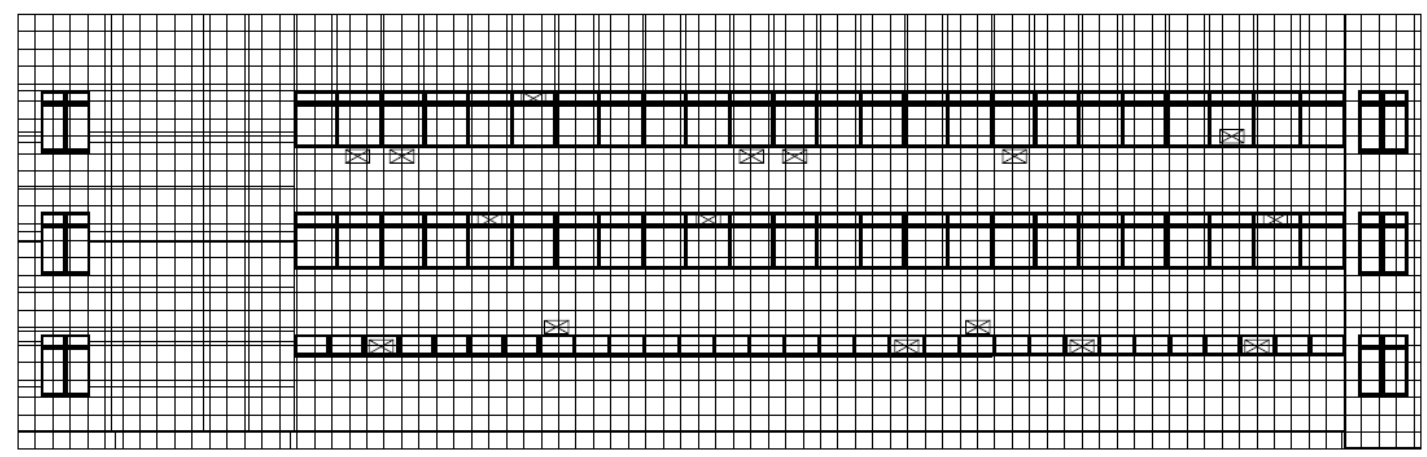

Figura 4: Fachada 1 com a malha de $0,25 \mathrm{~m}^{2}$ aplicada

O fator de danos permitiu uma estimativa do grau de degradação em que se encontrava o revestimento da edificação, além de relacioná-lo com a frequência de ocorrência de uma anomalia e suas causas, o que permitiu o entendimento do mecanismo de aparecimento desses danos, os quais, em muitos casos, são complexos (SILVA, 2014). A equação 1 mostra como é calculado o FD para cada pano de fachada.

$$
\mathrm{FD}(\mathrm{n})=(\operatorname{Ad}(\mathrm{n}) / \operatorname{At}(\mathrm{n})) * 100
$$

(Equação 1)

Em que:

FD(n) é o fator de danos para cada pano de fachada, em porcentagem (\%);

$\operatorname{Ad}(n)$ é a área afetada pelos danos na fachada $n, \mathrm{em} \mathrm{m}^{2}$;

$\operatorname{At}(\mathrm{n})$ é a área total da fachada $\mathrm{n}$, desconsidarando a área das aberturas, $\mathrm{em}^{2}$.

Buscando compatibilizar as diferentes áreas, foi calculado o coeficiente de correção (CCr) de cada amostra. Esse fator auxilia na comparação de manifestações patológicas de diferentes extensões, pois, em geral, quanto maior a área da fachada, esta está suscetível a maiores índices de degradação. O CCr pode ser calculado de acordo com a equação 2 , e o FD corrigido pode ser obtido a partir da equação 3.

$$
\begin{gathered}
\mathrm{CCr}=(\operatorname{Ar}(\mathrm{m}) / \operatorname{Ar}(\mathrm{n})) \\
\text { FDcorrigido = FDxCCr }
\end{gathered}
$$

Em que:

CCr é o coeficiente de correção da fachada analisada;

$\operatorname{Ar}(\mathrm{m})$ é a área total da menor fachada, em metros quadrados $\left(\mathrm{m}^{2}\right)$;

$\operatorname{Ar}(\mathrm{n})$ é a área total da fachada analisada, em metros quadrados $\left(\mathrm{m}^{2}\right)$;

FDcorrigido é o fator de danos corrigido, em porcentagem $(\%)$.

Foram calculados os fatores de danos para cada fachada, de acordo com o tipo de manifestação patológica observada, para verificar quais estão presentes e quais são mais recorrentes nas áreas analisadas. Os códigos utilizados para a identificação das anomalias foram: Biodeterioração por animais (BA); Biodeterioração por insetos (BI); Biodeterioração por manchamento (BM); Biodeterioração por vegetação (BV); Descolamentos (DC); Desplacamentos (DP); Fissuras (FI); Manchamento por sujidade (MS); Manchamento por umidade (MU); Manchamento por corrosão (MC); Eflorescência (EF); Desgaste no revestimento (DR); Desgaste na pastilha cerâmica (DPC); e Vandalismo (VA). 


\section{RESULTADOS}

A partir do método desenvolvido por Silva (2014), verificou-se o nível de degradação do revestimento do Anexo I do Campus da Saúde - UFRGS. A figura 5 mostra a porcentagem de ocorrência das manifestações patológicas em relação a todas os danos indentificados, em que o manchamento por sujidade apresentou $49 \%$ de ocorrência em relação a todas as anomalias observadas. O entorno da edificação apresenta grande movimentação de veículos, os quais são responsáveis por liberar partículas em suspensão, que, com o auxílio do vento e da chuva, acabam por contribuir no surgimento de manchamentos (PEREIRA et al., 2018).

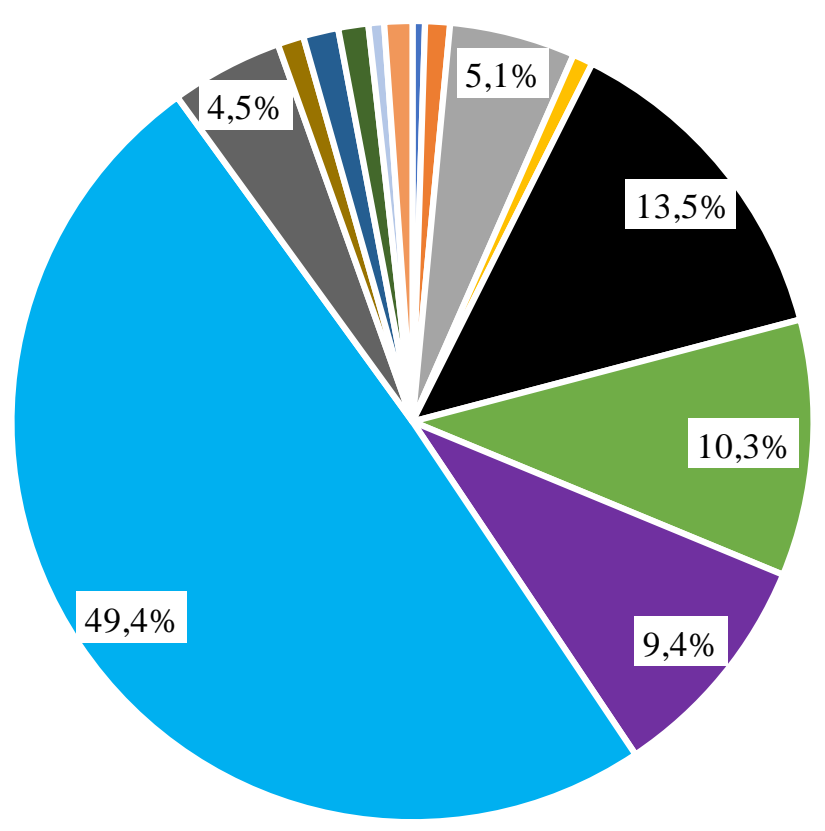

- Biodeterioração Animais (0,5 \%)

- Biodeterioração Insetos $(1,0 \%)$

- Biodeterioração Manchamento (5,1\%)

- Biodeterioração Vegetação $(0,8 \%)$

- Descolamento $(13,5 \%)$

- Desplacamento $(10,3 \%)$

- Fissuras $(9,4 \%)$

- Manchamento Sujidade $(49,4 \%)$

- Manchamento Umidade (4,5\%)

- Manchamento Corrosão (1,1\%)

- Eflorescência (1,4\%)

- Desgaste no Revestimento (1,2\%)

- Desgaste na Pastilha $(0,6 \%)$

- Vandalismo $(1,1 \%)$

Figura 5: Manifestações patológicas e porcentagens de ocorrência observadas nas fachadas da edificação

A perda de aderência, representada pelo descolamento e pelo desplacamento, foram as manifestações estrutural mais averiguadas (cerca de $24 \%$ dos danos). Estas podem ser decorrente da deformação originada pela variação térmica, somada à falha ou ausência de juntas de movimentação, ou por infiltração de umidade no revestimento, devido ao clima da cidade de Porto Alegre. A umidade é a causa de diversas manifestações patológicas verificadas na fachada, podendo desencadear e potencializar diversas anomalias (MADUREIRA et al., 2017).

O tipo de revestimento é um fator de grande influência para a ocorrência de anomalias, pois suas características podem auxiliar no desenvolvimentos dos danos. A figura 6 a mostra as manifestações patológicas no fulget e a figura $6 \mathrm{~b}$, na cerâmica. Verifica-se que o manchamento por sujidade está mais presente no fulget, o que pode ser devido à maior porosidade e rugosidade deste material, que contribui para que as partículas sólidas se fixem na superfície do pano da fachada. É possível averiguar também que há maior perda de aderência no revestimento cerâmico do que no revestimento de fulget. Isto pode ser causado pelo acúmulo de tensões devido aos diferentes coeficientes de deformação térmica dos materiais ou pelo final da vida útil do material colante que fixa essa pastilha na superfície (CHAVES, 2009), além de danos ou inexistência de juntas de movimentação. 


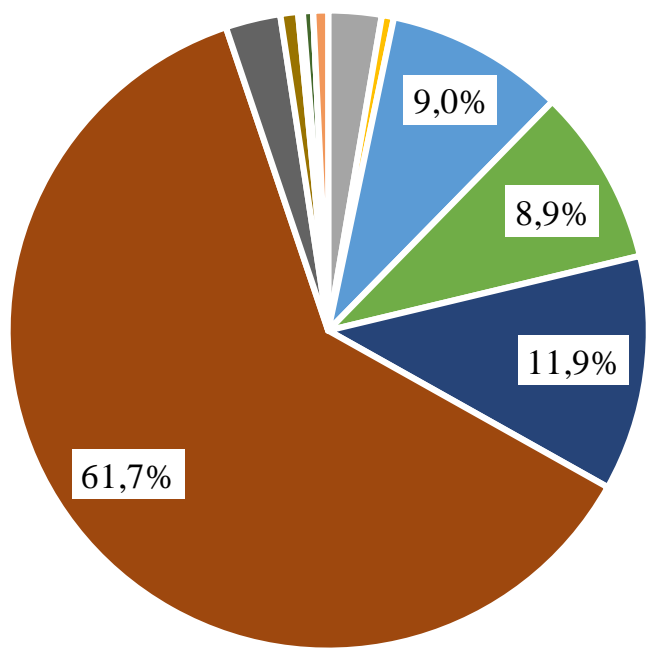

(a)

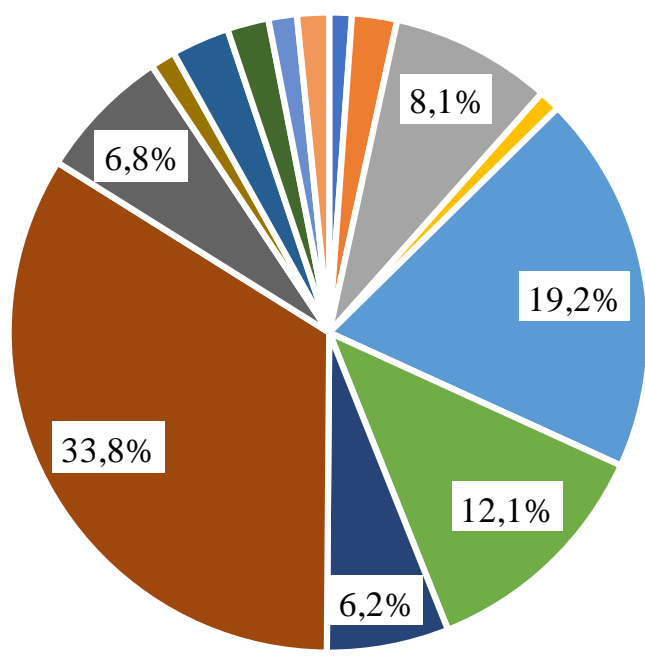

- Biodeterioração Animais (0,0 \%)

- Biodeterioração Insetos $(0,0 \%)$

- Biodeterioração Manchamento (2,7 \%)

- Biodeterioração Vegetação (0,6 \%)

- Descolamento (9,0\%)

- Desplacamento (8,9\%)

- Fissuras (11,9\%)

- Manchamento Sujidade $(61.7 \%)$

- Manchamento Umidade (2,8\%)

- Manchamento Corrosão (0,9\%)

- Eflorescência (0,2\%)

- Desgaste no Revestimento (0,5\%)

- Desgaste na Pastilha $(0,0 \%)$

- Vandalismo $(0,8 \%)$

- Biodeterioração Animais (1,1\%)

- Biodeterioração Insetos (2,3\%)

- Biodeterioração Manchamento $(8,1 \%)$

- Biodeterioração Vegetação (1,1\%)

- Descolamento (19,2\%)

- Desplacamento (12,1\%)

- Fissuras (6,2\%)

- Manchamento Sujidade (33.8\%)

- Manchamento Umidade (6,8\%)

- Manchamento Corrosão (1,3\%)

- Eflorescência (2,9\%)

- Desgaste no Revestimento (2,1\%)

- Desgaste na Pastilha (1,4\%)

- Vandalismo (1,6\%)

(b)

Figura 6: Ocorrência de manifestações patológicas nos diferentes tipos de revestimento: (a) fulget; (b) cerâmico

O fator de danos corrigido de cada pano de fachada, calculado de acordo com as equações 1, 2 e 3, conforme Silva (2014), permite a verificação de quais são as manifestações patológicas que estão presentes em cada área e seu nível de degradação, como mostrado na tabela 1. A anomalia manchamento por sujidade é verificada na grande maioria das fachadas, sendo o valor do fator de danos mais elevado nas regiões 2-E e 1, ambas constituídas de cerâmica. Estas estão voltadas para a orientação nordeste e noroeste, respesctivamente, e para a Rua Ramiro Barcelos, onde há maior fluxo de veículos e, portanto, estão sujeitas à grande quantidade de partículas suspensas, além de estarem expostas ao clima úmido da cidade (que possui umidade relativa anual média de 76,5\%) e do entorno. A fachada 1 , que possui ambos os revestimentos, foi a que apresentou maiores fatores de danos em relação a fissuras e a descolamentos, manifestações que podem interferir no desempenho estrutural da edificação. 
Tabela 1 - Fator de danos (N: Norte; S: Sul; E: Leste; O: Oeste; NE: Noroeste; SE: Sudeste; NO: Noroeste;

SO: Sudoeste)

\begin{tabular}{|c|c|c|c|c|c|c|c|c|c|c|c|c|c|c|}
\hline \multirow{2}{*}{$\begin{array}{c}\text { Dano } \\
\text { (Orientação) }\end{array}$} & \multicolumn{14}{|c|}{ Fator de danos $(\%)$} \\
\hline & $\mathrm{BA}$ & $\mathrm{BI}$ & BM & $\mathrm{BV}$ & DC & DP & FI & MS & MU & $\mathrm{MC}$ & $\mathrm{EF}$ & DR & DPC & $\overline{\text { VA }}$ \\
\hline $\begin{array}{c}\text { Fachada } 1 \\
\text { (SE) }\end{array}$ & 1,1 & - & - & - & 6,3 & - & 3,3 & 20,5 & - & - & 0,8 & - & - & 1,0 \\
\hline $\begin{array}{l}\text { Fachada } 2 \\
\text { (SE) }\end{array}$ & - & - & 1,7 & 0,7 & 0,2 & 1,0 & 1,9 & 12,0 & - & - & 2,0 & - & 1,4 & - \\
\hline $\begin{array}{c}\text { Fachada 2-A } \\
\text { (SE) }\end{array}$ & - & - & 0,3 & - & 1,2 & 2,8 & 1,8 & 9,3 & 14,3 & 0,5 & 3,2 & - & - & - \\
\hline $\begin{array}{l}\text { Fachada 2-B } \\
\text { (SE) }\end{array}$ & - & - & 0,5 & 0,5 & - & - & 1,0 & 1,8 & - & - & - & 0,7 & - & - \\
\hline $\begin{array}{l}\text { Fachada 2-C } \\
\text { (SO) }\end{array}$ & - & - & - & - & 0,7 & 0,1 & - & 0,6 & - & - & - & - & - & - \\
\hline $\begin{array}{l}\text { Fachada 2-D } \\
\text { (E) }\end{array}$ & - & - & - & - & - & - & - & 0,7 & - & 0,1 & - & 1,6 & - & - \\
\hline $\begin{array}{l}\begin{array}{c}\text { Fachada 2-E } \\
\text { (E) }\end{array} \\
\end{array}$ & - & 1,6 & 2,0 & - & - & 1,1 & 4,0 & 31,9 & 3,4 & 2,2 & - & - & - & - \\
\hline Fachada $3(\mathrm{E})$ & - & 2,0 & 2,4 & - & 9,9 & 1,4 & 0,7 & 12,5 & - & - & - & - & - & - \\
\hline $\begin{array}{c}\text { Fachada } 4 \\
(\mathrm{~N})\end{array}$ & - & - & 1,1 & - & 2,8 & 2,3 & 0,2 & 5,4 & - & 0,3 & - & - & - & 1,0 \\
\hline $\begin{array}{c}\text { Fachada } 5 \\
(\mathrm{O})\end{array}$ & - & - & - & - & 1,2 & 1,5 & 2,0 & 8,6 & - & - & - & - & - & - \\
\hline $\begin{array}{c}\text { Fachada } 6 \\
\text { (NO) }\end{array}$ & - & - & - & - & 3,5 & 4,5 & 1,0 & - & 0,5 & - & - & - & - & - \\
\hline $\begin{array}{c}\text { Fachada } 7 \\
(\mathrm{NE})\end{array}$ & - & - & - & 0,2 & 2,2 & 3,3 & 3,3 & 10,6 & 4,4 & - & - & - & - & 0,6 \\
\hline Fachada $8(\mathrm{~S})$ & - & - & 0,2 & 0,1 & 1,0 & 1,7 & 2,5 & 17,6 & 1,1 & 0,2 & - & - & - & - \\
\hline $\begin{array}{c}\text { Fachada } 9 \\
(\mathrm{O})\end{array}$ & - & - & 3,7 & - & 1,4 & 5,5 & 1,3 & 10,0 & 0,7 & - & - & - & - & - \\
\hline $\begin{array}{c}\text { Fachada } 10 \\
(\mathrm{NO})\end{array}$ & - & - & 1,0 & 0,5 & 0,5 & 1,7 & 1,3 & 2,6 & - & 1,1 & - & - & - & - \\
\hline $\begin{array}{l}\text { Fachada } 11 \\
\text { (SO) }\end{array}$ & - & - & - & - & - & - & 2,0 & 2,8 & - & - & - & - & - & - \\
\hline
\end{tabular}

Para aferir qual região mais apresenta danos, foram calculados o fator de danos geral de cada região e, assim, foi identificada aquela com maior concentração de anomalias. As figuras 7 e 8 mostram o fator de danos para cada pano de fachada e o fator de danos quando considera-se separadamente os dois tipos de revestimentos analisados. 

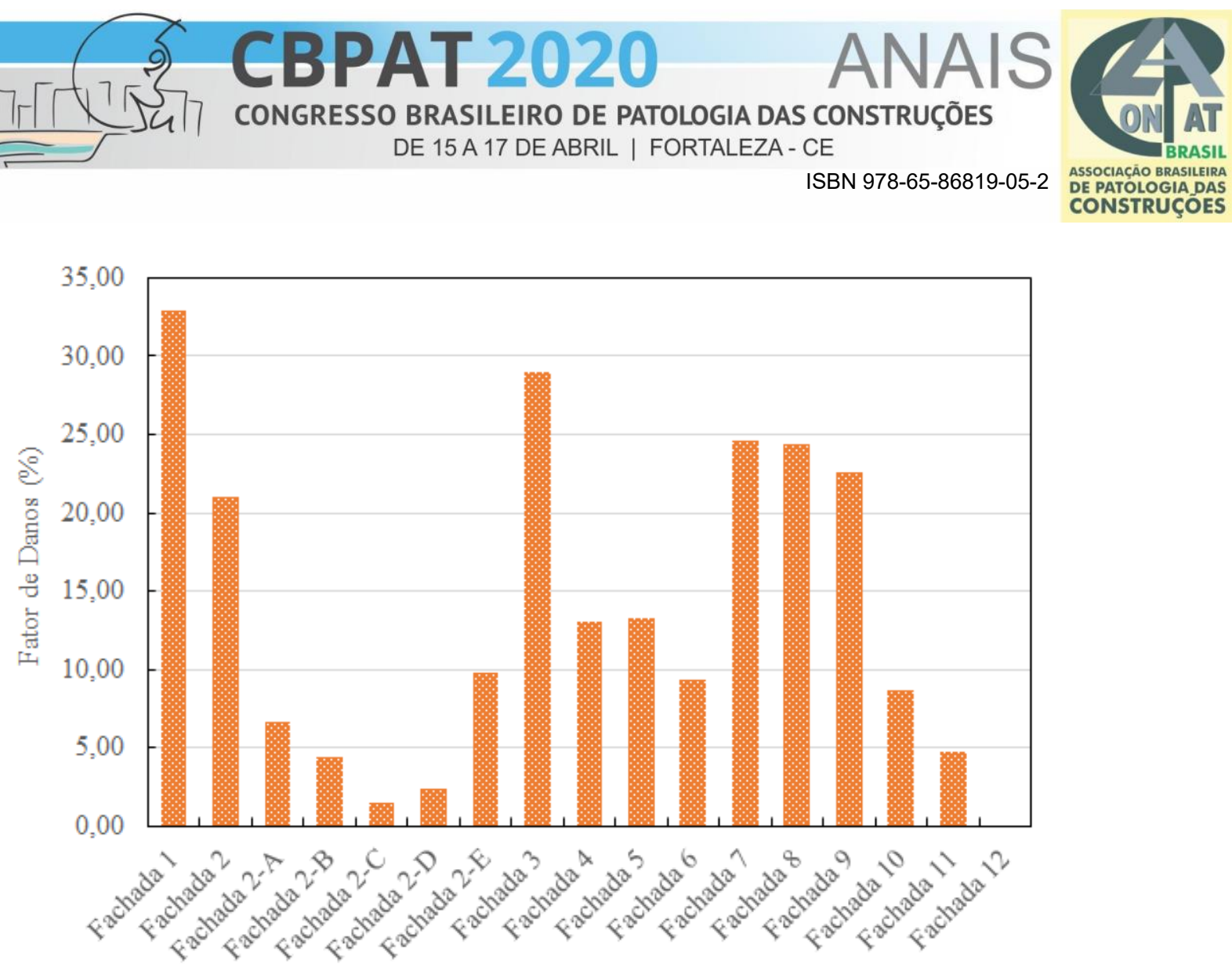

Figura 7: Fator de danos corrigido para cada região

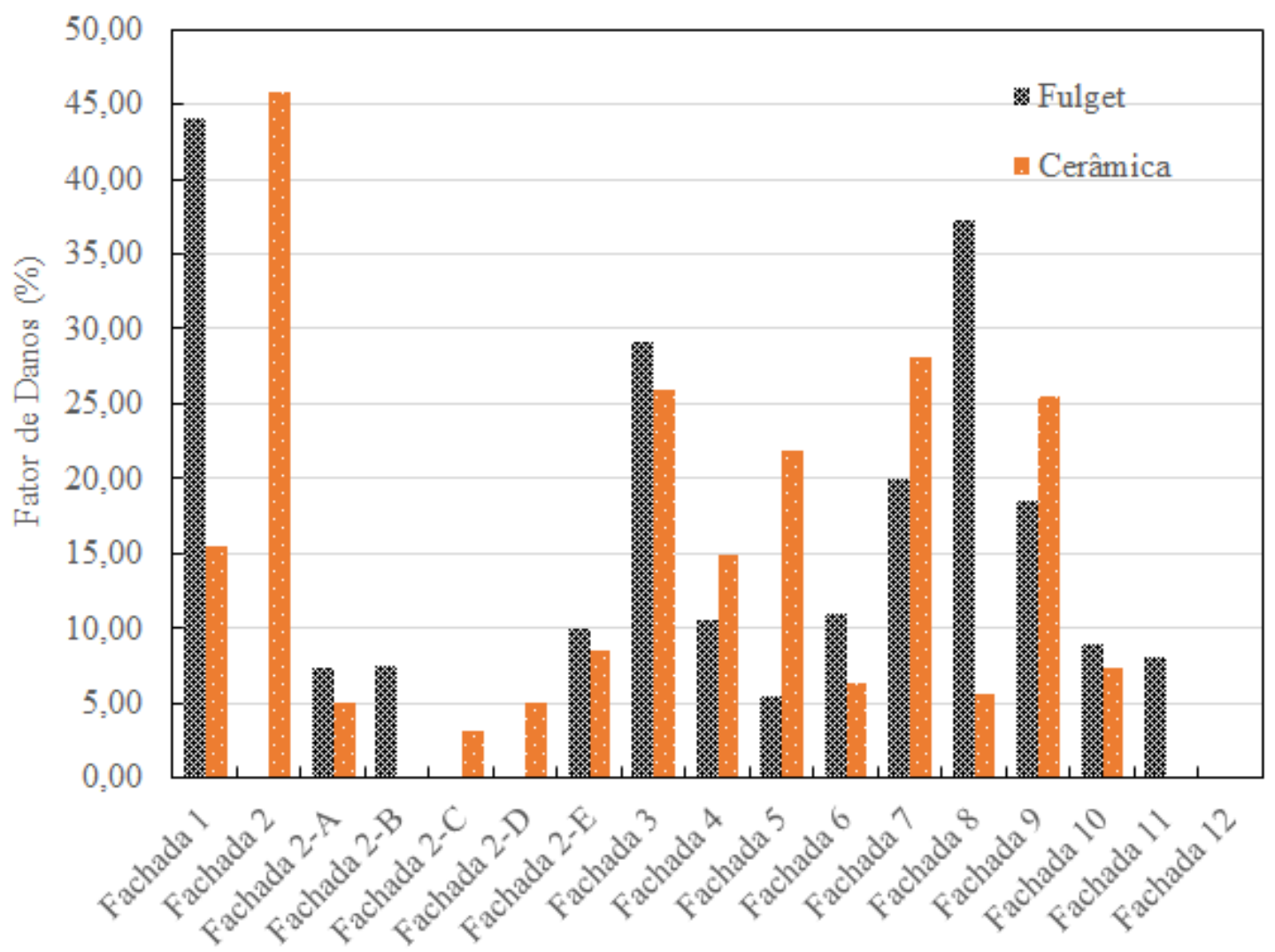

Figura 8: Fator de danos corrigido para cada região, de acordo com o tipo de revestimento

A fachada 1 é que apresenta maior fator de danos e, como já citado anteriormente, manifestações de ordem estética e estruturais, o que pode ser um indicativo do grau elevado de degradação sofrida por essa região. Esse pano de fachada 
está voltado para a orientação sudeste, recebendo a maior intensidade de chuva dirigida na cidade de Porto Alegre. Devido a combinação deste fator com a umidade, com o gradiente de temperatura sofrido pelo revestimento com a poluição do entorno, e com a falha ou inxistência de juntas de movimentação, a área apresenta elevado grau de deterioração. Além desta, as fachadas 2, 3, 7, 8 e 9 também possuem fator de danos acima de $15 \%$.

Em relação ao tipo de revestimento mais deteriorado, podemos reafirmar, a partir do fator de danos, que o fulget é o que apresenta maiores fatores de degradação quando comparado com a cerâmica, em sua maioria. É importante salientar que já houve queda e/ou retirada de placas de fulget que representavam risco à segurança dos usuários da edificação e alguns locais estavam interditados. Essas regiões estão, em sua grande maioria, nas fachadas 7, 8, 9 e 10, as quais apresentam fatores de danos elevados, evidenciando a urgência de uma ação de intervenção para mitigar os futuros danos que as degradações sofridas por esse tipo de revestimento podem causar aos usuários da edificação.

\section{CONCLUSÕES}

As fachadas do edifício Anexo I do Campus da Saúde da Universidade Federal do Rio Grande do Sulsão revestidas, em sua maioria, por fulget e pastilhas cerâmicas. Esse prédio contém diversas salas de aula e laboratórios e, portanto, recebe muitos visitantes ao dia, o que evidencia a necessidade da identificação e quantificação das principais manifestações patológicas presentes no revestimento das fachadas que, além do efeito estético, podem oferecer riscos aos usuários.

Entre as manifestações patológicas com maior incidência, destaca-se o manchamento por sujidade, seguido pelos desplacamentos e descolamentos. Vários fatores podem estar relacionados ao surgimento de manchamentos por sujidade, como as condições relacionadas à localização e ao entorno da edificação (vento, chuva dirigida, vegetação e tráfego de veículos), à rugosidade dos revestimentos (especialmente do fulget) e, possivelmente, à deficiência e/ou ausência de detalhes construtivos importantes (por exemplo, juntas). Também constatou-se que, dentre as regiões do edifício, a fachada 1 foi a que apresentou a maior incidência de manifestações patológicas em comparação com as demais.

Ressalta-se o descolamento e o desplacamento do revestimento de fulget como pontos críticos nas fachadas, uma vez que, no levantamento realizado, foram constatadas grandes frações que se desprenderam da fachada e caíram no entorno, além de outras regiões que estavam descoladas do substrato, porém ainda presas nos arredores, mas que podem vir a se destacar e provocar danos ao patrimônio alheio ou até aos usuários que ali trafegam.

Por fim, esse levantamento de danos contribui para a conservação do Anexo I do Campus da Saúde, uma vez que oferece subsídios para realizar propostas de intervenção e manutenção, de modo a possibilitar a melhor utilização da edificação, de forma segura por parte dos usuários, e a preservar a importante função que presta à sociedade.

\section{REFERÊNCIAS}

ABREU, M.; LEITÃO, V.; LUCAS, J. C. Modelling the behaviour of ceramic tile coverings. In: Qualicer, 2014, Castellón. Anais eletrônicos... Castellón, 2014. p. II-3-17.

ASSOCIAÇÃO BRASILEIRA DE NORMAS TÉCNICAS. NBR 13755: Revestimentos cerâmicos de fachadas e paredes externas com utilização de argamassa colante - Projeto, execução, inspeção e aceitação - Procedimento. Rio de Janeiro, 2017.

AUTODESK. Software gráfico AutoCAD 2018. Califórnia, 2017.

CASCUDO, O.; CARASEK, H. Avaliação e restauração de revestimentos de argamassa. In: II Simpósio Brasileiro de Tecnologia das Argamassas, 1997, Salvador. Anais eletrônicos... Salvador: 1997. p. 383-393.

CHAVES, A. M. V. A. Patologia e reabilitação de revestimentos de fachadas. Minho, 2009. 176p. Dissertação de Mestrado em Engenharia Civil, Escola de Engenharia, Universidade do Minho.

DAL FORNO, M. A. R.; MATOS, V. V. L. Parâmetros de qualidade da água do Arroio Dilúvio, Porto Alegre/RS.

Boletim Geográfico do Rio Grande do Sul, Porto Alegre, n. 27, p. 112-135, mar. 2016. 
FLORES-COLEN, I.; BRITO, J. de; FREITAS, V. P. de. Métodos de Verificação do Desempenho em Serviço de Fachadas Rebocadas. In: $3^{\circ}$ Encontro Sobre Patologia E Reabilitação De Edifícios - PATORREB, 2009, Porto. Anais eletrônicos... Porto: FEUP, 2009. p. 651-655.

INSTITUTO NACIONAL DE METEREOLOGIA. Gráficos climatológicos: (1931-1960 e 1961-1990). Brasília. Disponível em: http://www.inmet.gov.br/portal/index.php?r=clima/graficosClimaticos. Acesso em: 20 jun. 2019.

KISS, P. Tecnologia: Efeitos especiais. Edição 41. Téchne, Edição 41, Julho/1999.

KONDO, S. T. Subsídios para seleção dos principais revestimentos de fachadas de edifícios. 2003. 71f. Monografia para MBA em Tecnologia e Gestão na Produção de Edifícios, Escola Politécnica da Universidade de São Paulo, São Paulo, 2003.

MADUREIRA, S.; FLORES-COLEN, I.; BRITO, J.; PEREIRA, C. Maintenance planning of facades in current buildings. Construction and Building Materials, v. 147, p. 790-802, 2017.

PAIM, A.; ANDRADE, A.; POLI, C.; CECHIN, G.; ALMEIDA, J.; ROJAS, R.; MASUERO, A. Diagnóstico das manifestações patológicas no revestimento fulget da fachada do centro de combustíveis da UFRGS. In: Congresso Brasileiro de Patologia das Construções - CBPAT, 2016, Belém. Anais eletrônicos... Belém, 2016. p. 897-908.

PEREIRA, C.; BRITO, J.; SILVESTRE, J. Contribution of humidity to the degradation of façade claddings in current buildings. Engineering Failure Analysis, v. 90, p. 103-115, 2018.

PEZZATO, L. M. Patologias no sistema revestimento cerâmico: um estudo de casos em fachadas. 2010. $160 \mathrm{f}$. Dissertação (Mestrado em Arquitetura e Urbanismo) - Escola de Engenharia de São Carlos da Universidade de São Paulo, São Carlos, 2010.

REBELO, C. R. Projeto e execução de revestimento cerâmico - interno. 2010. 55f. Monografia para Especialização em Construção Civil, Escola de Engenharia da Universidade Federal de Minas Gerais, Belo Horizonte, 2010.

SILVA, M. N. B. Avaliação Quantitativa da Degradação e Vida Útil de Revestimentos de Fachada - Aplicação ao Caso de Brasília/DF. Brasília, 2014. 297 p. Tese de Doutorado em Estruturas e Construção Civil, Universidade de Brasília.

TERRA, R. C. Levantamento de manifestações patológicas em revestimentos de fachadas das edificações da cidade de Pelotas. Porto Alegre, 2001. 133p. Dissertação de Mestrado em Engenharia Civil, Universidade Federal do Rio Grande do Sul.

ZINI, A.; DALAZEN, C. D. A.; MASUERO, G. B.; BERSH, J. D.; ANDRADE NETO, J. S.; KIRCHNER, L. S.; PY, L. G.; BIANCHETTI, L .G.; MAZZUCO, M.; DESSUY, T. Y.; SILVA, T. S. M.; PASINATTO, V. Diagnóstico das manifestações patológicas das fachadas do prédio do Anexo I - Campus Saúde - UFRGS e proposta de intervenção. Relatório Técnico, Disciplina de Patologia das Edificações - PPGCI/UFRGS, 2019. 